\title{
PENGARUH KOMPENSASI NON FINANSIAL, LINGKUNGAN KERJA FISIK DAN KOMPETENSI TERHADAP KEPUASAN KERJA KARYAWAN
}

\author{
I Made Dwi Putra Arimbawa ${ }^{1}$ \\ I Gusti Ayu Ketut Giantari ${ }^{2}$
}

\author{
${ }^{1,2}$ Fakultas Ekonomi dan Bisnis Universitas Udayana, Bali, Indonesia \\ e-mail:dhedwick@yahoo.com
}

\begin{abstract}
ABSTRAK
Tujuan dari penelitian ini untuk mengetahui pengaruh kompensasi non finansial, lingkungan kerja fisik dan kompetensi menjelaskan terhadap kepuasan kerja karyawan pada PT. Bank Perkreditan Rakyat Tish Gianyar. Ukuran sampel sebanyak 39 orang karyawan yang di ambil dengan menggunakan metode penentuan sampling jenuh. Pengumpulan data dilakukan dengan observasi, wawancara dan penyebaran kuesioner. Teknik analisis yang digunakan adalah regresi linier berganda. Hasil analisis menunjukan bahwa kompensasi non finansial, lingkungan kerja fisik dan kompetensi berpengaruh positif terhadap kepuasan kerja karyawan. Untuk menumbuhkan rasa kepuasan kerja karyawan kompensasi non finansial dari pihak pimpinan penting untuk terus memberi motivasi terhadap karyawan. Lingkungan kerja fisik dan kompetensi juga harus terus ditingkatkan untuk menjaga lingkungan kerja yang telah ada.
\end{abstract}

Kata Kunci: kompensasi non finansial, lingkungan kerja fisik, kompetensi, kepuasan kerja

\begin{abstract}
The purpose of this study is to determine the effect of non-financial compensation, physical work environment and competence to explain the job satisfaction of employees at PT. Gianyar Tish Rural Credit Bank. The sample size of 39 employees was taken using the method of determining saturated sampling. Data collection is done by observation, interviews and questionnaires. The analysis technique used is multiple linear regression. The results of the analysis show that non-financial compensation, physical work environment and competence have a positive effect on employee job satisfaction. To foster a sense of job satisfaction, non-financial compensation employees from the leadership are important to continue to motivate employees. The physical work environment and competence must also be continuously improved to maintain the existing work environment.
\end{abstract}

Keywords: non-financial compensation, physical work environment, competence, job satisfaction 


\section{PENDAHULUAN}

Bank merupakan badan usaha keuangan yang keberadaannya untuk melayani masyarakat. Bank didirikan di samping untuk melayani masyarakat dalam bidang keuangan juga merupakan suatu badan usaha yang bertujuan untuk memperoleh keuntungan. Untuk itu bank hendaknya mampu memberikan pelayanan yang dapat memuaskan masyarakat. Pelayanan yang diharapkan masyarakat adalah pelayanan yang baik, yaitu pelayanan yang berkualitas. Semakin baik pelayanan yang diberikan kepada masyarakat maka prakarsa masyarakat untuk proaktif dalam menggunakan jasa perbankan akan semakin tinggi.

Setiap perusahaan memerlukan sumber daya untuk mencapai tujuannya. SDM adalah harta atau aset paling berharga dan paling penting yang dimiliki oleh suatu organisasi, karena keberhasilan organisasi sangat ditentukan oleh manusia (Ardana dkk., 2012:3). SDM dalam suatu perusahaan harus memiliki kompetensi dan kinerja tinggi agar dapat melaksanakan fungsi-fungsi manajemennya, oleh karena itu pengelolaan SDM yang tidak hanya mengakui pentingnya efisien dan efektivitas kerja, namun juga mengakui pentingnya nilai karyawan, karena salah satu elemen pokok dalam organisasi adalah kemampuan karyawan yang memberikan upaya secara nyata pada sistem kerjasama organisasi (Nongkeng dkk., 2011). Pendapat serupa juga dinyatakan oleh Voon et al. (2011) bahwa karyawan merupakan aset paling penting bagi organisasi dan organisasi harus memiliki pemimpin yang mampu memimpin dan memotivasi karyawan untuk mencapai tujuan organisasi. 
I Made Dwi Putra Arimbawa, Pengaruh Kompensasi Non.....

Kepuasan kerja adalah suatu perasaan positif tentang pekerjaan seseorang yang merupakan hasil dari sebuah evaluasi karakteristiknya (Robbins dan Judge 2008:107). Javad dan Davood (2012) kepuasan kerja adalah reaksi afektif umum atau global yang dimiliki individu terhadap pekerjaan mereka. Umar (2010) menyatakan bahwa kepuasan kerja memperlihatkan perasaan karyawan tentang menyenangkan atau tidaknya pekerjaan. Hal yang serupa juga dinyatakan oleh (Mathis dan Jackson, 2010:98) bahwa kepuasan kerja adalah keadaan emosional yang positif yang merupakan hasil dari evaluasi pengalaman kerja seseorang. Kepuasan kerja sulit didefinisikan karena rasa puas itu bukan keadaan yang tetap melainkan dapat dipengaruhi dan diubah oleh kekuatan-kekuatan baik dari dalam maupun dari luar lingkungan kerja (Suwatno dan Priansa, 2011).

Menciptakan kepuasan kerja bagi karyawan, perusahaan bisa melakukannya dengan cara memberikan kompensasi yang efektif. Kompensasi yang efektif disini maksudnya kompensasi yang bisa dirasakan manfaatnya oleh karyawan dan dapat meningkatkan kepuasan kerja bagi mereka. Kompensasi itu bisa berupa kompensasi finansial maupun kompensasi non finansial. Menurut Utami (2005: 23) kompensasi non finansial ada dua, yaitu pekerjaan dan lingkungan pekerjaan.

Kompensasi sering kali dianggap sebagai pemicu utama ketidakpuasan karyawan yang pada akhirnya menyebabkan ketiadaan loyalitas. Bila merasa tidak loyal, karyawan mungkin tidak bekerja seperti seharusnya, dan pada akhirnya perusahaan akan sulit mempertahankan karyawan, dan juga sulit mengharapkan kepuasan kerja karyawan. Apabila harapan karyawan mengenai kompensasi yang 
demikian dapat diwujudkan oleh perusahaan, maka karyawan akan merasa diperlakukan secara adil oleh perusahaan (Muljani, 2002).

Pengembangan atau peningkatan kepuasan karyawan dapat dilakukan dengan membayarkan kompensasi menurut pasar, aman, mengandung nilai-nilai kekeluargaan, dan mampu memenuhi kebutuhan karyawan tersebut (Aityan, 2011:4). Hal ini untuk membantu perusahaan dalam mencapai tujuan keberhasilan strategi perusahaan dan menjamin terciptanya keadilan internal maupun eksternal (Suswardji dkk., 2012). Beberapa peneliti sepakat bahwa uang bisa menjadi motivator yang baik, karena uang adalah bagian dari kebutuhan manusia. Selain itu, orang-orang yang sangat miskin secara finansial menunjukkan peningkatan kebahagiaan ketika pendapatan mereka meningkat (Omar et al., 2013).

Berdasarkan penelitian yang dilakukan oleh Hameed et al. (2009) faktor lain yang dapat menjadikan karyawan puas dalam bekerja ialah dengan adanya lingkungan kerja yang aman dan nyaman. Lingkungan kerja yang memuaskan bagi karyawan dapat meningkatkan kinerja, sebaliknya lingkungan kerja yang tidak memadai dapat menurunkan kinerja karyawan dan akhirnya motivasi kerja karyawan menurun. Pech dan Slade (dalam Leblebici, 2012) juga menyatakan bahwa meningkatnya kepuasan karyawan dipengaruhi juga dengan adanya lingkungan kerja yang positif.

Lingkungan kerja fisik yang nyaman akan mampu meningkatkan kepuasan kerja karyawan (Setiawan, dan Sariyathi, 2013). Lingkungan kerja fisik berpengaruh penting untuk menciptakan dan meningkatkan kepuasan kerja para karyawan (Wibowo, dkk., 2014). Lingkungan kerja fisik dalam perusahaan sangat 
penting untuk diperhatikan manajemen. Meskipun lingkungan kerja fisik tidak terkait langsung dalam proses produksi, namun lingkungan kerja fisik mempunyai pengaruh langsung terhadap pegawai yang melaksanakan proses produksi (Cahyadi, 2013). Pernyatan serupa juga diungkapkan oleh Mike (dalam Shikdar, 2002) bahwa tempat kerja yang efektif adalah sebuah lingkungan dimana hasil yang dapat dicapai seperti yang diharapkan oleh manajemen.

Kompetensi menurut Wibowo (2012:324) adalah suatu kemampuan untuk melaksanakan suatu pekerjaan yang dilandasi atas keterampilan dan pengetahuan serta didukung oleh sikap kerja yang dituntut oleh pekerjaan tersebut. Berdasarkan pengertian tersebut dapat disimpulkan bahwa kompetensi adalah kemampuan dalam kerja dengan mengintegrasikan pengetahuan, keterampilan, kemampuan serta nilai-nilai pribadi berdasarkan pengalaman dan pembelajaran dalam rangka pelaksanaan tugasnya secara professional, efektif dan efisien. Hasil penelitian Sari (2013) menemukan bahwa kompetensi dan lingkungan kerja berpengaruh signifikan dan positif terhadap kepuasan kerja.

Bank Perkreditan Rakyat merupakan salah satu Bank di Indonesia yang hadir dan tumbuh sebagai bank yang mampu idealisme usaha dengan nilai-nilai rohani yang melandasi kegiatan operasinya. Salah satunya adalah BPR Tish di Kabupaten Gianyar yang memiliki misi untuk mewujudkan pertumbuhan dan keuntungan yang berkesinambungan dengan cara selalu berupaya untuk memastikan memberikan pelayanan dan kenyamanan bagi nasabah agar bisa mendapatkan nilai lebih dari sekedar kepuasan nasabah yang mereka dapatkan sampai diluar ruangan BPR. Sehingga kualitas pelayanan dan inovasi yang 
diberikan oleh BPR merupakan andalan mereka dalam memenangkan hati nasabah ditengah persaingan yang begitu kompetitif dalam dunia perbankkan saat ini.

PT. BPR Tish di Kabupaten Gianyar dalam menuju visi dan misi sudah seharusnya memiliki karyawan yang penuh semangat dalam mengerjakan segala tugas-tugasnya sehingga visi dan misi perusahaan dapat tercapai. BPR Tish ini yang beralamat di Jln. Raya Batubulan No. 27X Kecamatan Sukawati, Kabupaten Gianyar, dengan jumlah karyawan sebanyak 40 orang.

Berdasarkan hasil pengamatan dan wawancara dengan beberapa karyawan, ditemukan permasalahan yang berhubungan dengan Kompensasi non finansial dimana karyawan sulit untuk mendapatkan ijin libur saat bekerja dan mengajukan cuti untuk alasan tertentu serta dimana kurangnya perhatian pimpinan dalam memberikan motivasi terhadap bawahan. Permasalahan lain yang berkaitan dengan lingkungan kerja fisik masih terlihat ruangan yang kurang luas dan penataan peralatan kerja yang masih perlu penyempurnaan dan permasalahan yang berkaitan dengan kompetensi dimana PT. Bank Perkreditan Rakyat Tish kurang menerapkan kompetensi dalam bekerja sehingga kecilnya peluang karyawan dalam berkarir.

Permasalahan lain yang berkaitan dengan kepuasan kerja dimana ditemukannya gejala-gejala timbulnya ketidakpuasan kerja pada karyawan PT. Bank Perkreditan Rakyat Tish Gianyar, dimana kepuasan kerja memiliki hubungan yang tidak searah dengan tingkat absensi, jika suatu tingkat absensi dalam suatu perusahaan tinggi, maka kepuasan kerja akan menurun, begitu juga 
I Made Dwi Putra Arimbawa, Pengaruh Kompensasi Non.....

sebaliknya, jika tingkat absensi rendah, maka kepuasan kerja akan meningkat. Dilihat dari tingkat absensi yang tinggi, tidak dipatuhinya jam kerja kantor yang sudah ditetapkan dalam peraturan perusahaan, seperti karyawan sering datang terlambat dan bahkan pulang kerja lebih awal. Berikut ini tingkat kehadiran karyawan PT. Bank Perkreditan Rakyat Tish Gianyar dapat dilihat pada Tabel 1. sebagai berikut:

\section{Tabel 1.}

Tingkat Absensi Karyawan PT. Bank Perkreditan Rakyat Tish Gianyar Cabang Utama Denpasar Tahun 2017

\begin{tabular}{|c|c|c|c|c|c|c|}
\hline Bulan & $\begin{array}{c}\text { Jumlah } \\
\text { Karyawa } \\
\text { n } \\
\text { (Orang) }\end{array}$ & $\begin{array}{c}\text { Jumlah } \\
\text { Hari } \\
\text { Kerja } \\
\text { (Hari) }\end{array}$ & $\begin{array}{c}\text { Jumlah Hari } \\
\text { Kerja } \\
\text { Seharusnya } \\
\text { (Hari) }\end{array}$ & $\begin{array}{c}\text { Jumlah } \\
\text { Absensi } \\
\text { (Hari) }\end{array}$ & $\begin{array}{c}\text { Jumlah } \\
\text { Hari } \\
\text { Senyatanya } \\
\text { (Hari) }\end{array}$ & $\begin{array}{c}\text { Persentase } \\
\text { Absensi } \\
(\%)\end{array}$ \\
\hline $\mathrm{A}$ & $\mathrm{B}$ & $\mathrm{C}$ & $\mathrm{D}=\mathrm{B} \times \mathrm{C}$ & $\mathrm{E}$ & $F=D-E$ & $\mathrm{G}=\mathrm{E} / \mathrm{Dx} 100 \%$ \\
\hline Januari & 40 & 23 & 920 & 38 & 882 & 2,42 \\
\hline Februari & 40 & 17 & 680 & 28 & 652 & 2,42 \\
\hline Maret & 40 & 23 & 920 & 36 & 884 & 2,55 \\
\hline April & 40 & 26 & 1040 & 38 & 1002 & 2,73 \\
\hline Mei & 40 & 22 & 880 & 34 & 846 & 2,58 \\
\hline Juni & 40 & 24 & 960 & 38 & 922 & 2,52 \\
\hline Juli & 40 & 21 & 840 & 34 & 806 & 2,47 \\
\hline Agustus & 40 & 25 & 1000 & 32 & 968 & 3,12 \\
\hline September & 40 & 19 & 760 & 32 & 728 & 2,37 \\
\hline Oktober & 40 & 25 & 1000 & 32 & 968 & 3,12 \\
\hline November & 40 & 26 & 1040 & 28 & 1012 & 3,71 \\
\hline Desember & 40 & 23 & 920 & 32 & 888 & 2,87 \\
\hline Jumlah & 480 & 274 & 10.964 & 402 & 10.558 & 32,88 \\
\hline Rata-rata & & 22,83 & 913 & 33,5 & 879,83 & 2,74 \\
\hline
\end{tabular}

Sumber : PT. Bank Perkreditan Rakyat Tish Gianyar, 2017

Dari Tabel 1. dapat diketahui bahwa tingkat absensi karyawan tahun 2016 cenderung mengalami fluktuasi setiap bulannya, dimana tingkat absensi berkisar antara 28-37 hari (2,9 persen-3,85persen) atau rata-rata 33,42 hari (3,45persen), cukup tinggi karena berada di atas 3 persen (Gorda, 2006:185). Melihat dari tingginya tingkat absensi, dapat dikatakan bahwa semangat kerja karyawan masih kurang sehingga diprediksi kepuasan kerja karyawan masih rendah. 
Melihat dari uraian di atas, kepuasan karyawan PT. Bank Perkreditan Rakyat Tish Gianyar dipengaruhi oleh beberapa variabel. antara lain, kompensasi non finansial, lingkungan kerja fisik dan kompetensi karyawan. Dengan demikian sangatlah penting untuk diteliti secara mendalam mengenai pengaruh kompensasi non finansial, lingkungan kerja fisik dan kompetensi terhadap kepuasan karyawan.

Tobing (2009) mengungkapkan bahwa kompensasi non finansiaal memiliki pengaruh yang positif dan signifikan terhadap kepuasan kerja pekerja. Dimana pekerja yang merasa puas dengan adanya kompensasi non finansial yang diperoleh akan menunjukkan peningkatan kinerjanya dengan memberikan pelayanan yang terbaik dan bekerja dengan maksimal. Penelitian yang dilakukan oleh (Pratama, dkk., 2014) yang menemukan bahwa kompensasi (finansial dan non finansial) berpengaruh signifikan terhadap kepuasan kerja karyawan. Demikian pula dengan penelitian yang dilakukan oleh Reskiputri (2015) menemukan bahwa kompensasi non finansial berpengaruh signifikan terhadap kepuasan kerja karyawan. Dari uraian di atas dapat disusun hipotesis pertama yaitu.

$\mathrm{H}_{1}$ : Kompensasi non finansial berpengaruh positif dan signifikan terhadap kepuasan kerja

Lingkungan kerja fisik yang baik akan memotivasi karyawan untuk bekerja lebih giat sehingga menghasilkan produk yang berkualitas, hal ini meciptakan kepuasan kerja bagi karyawan yang bersangkutan. Ini berarti lingkungan kerja fisik berpengaruh terhadap kepuasan kerja karyawan. Kondisi ini sesuai dengan 
hasil penelitian yang dilakukan oleh Reskiputri (2015) bahwa lingkungan kerja fisik berpengaruh signifikan terhadap kepuasan kerja karyawan. Disamping itu sesuai pula dengan hasil penelitian yang dilakukan oleh Wibowo dkk. (2014) yang menemukan bahwa lingkungan kerja fisik berpengaruh secara positif dan signifikan terhadap kepuasan kerja karyawan.

Wahyudi (2013) dalam penelitiannya menyatakan lingkungan kerja fisik terdapat pengaruh positif dan signifikan terhadap kepuasan kerja karyawan pada PT. KBA TUR. Septiadi, dan Supartha (2013) dalam penelitiannya menyatakan lingkungan kerja fisik berpengaruh positif dan signifikan terhadap kepuasan kerja karyawan PT. BPR Sriartha Lestari. Berdasarkan uraian di atas maka dapat disusun hipotesi ke dua sebagai berikut.

$\mathrm{H}_{2}$ : Lingkungan kerja fisik berpengaruh positif dan signifikan terhadap kepuasan kerja karyawan

Boyatzis dalam Hutapea dan Thoha (2008) menyatakan kompetensi adalah kapasitas yang ada pada seseorang yang bisa membuat orang tersebut mampu memenuhi apa yang disyaratkan oleh pekerjaan dalam suatu organisasi sehingga organisasi tersebut mampu mencapai hasil yang diharapkan. Mangkunegara (2009: 41) menyatakan bahwa, kompetensi SDM adalah kompetensi yang berhubungan dengan pengetahuan, keterampilan dan karakteristik pribadi yang mempengaruhi secara langsung kepuasan kerjanya.

Kedua pernyataan tersebut mengindikasikan betapa pentingnya kompetensi bagi sumber daya manusia di dalam suatu organisasi ataupun perusahaan dalam 
rangka meningkatkan kepuasan kerja menuju kinerja yang lebih baik. Berdasarkan uraian di atas maka dapat disusun hipotesi ke tiga sebagai berikut.

$\mathrm{H}_{3}$ : Kompetensi berpengaruh positif dan signifikan terhadap kepuasan kerja karyawan

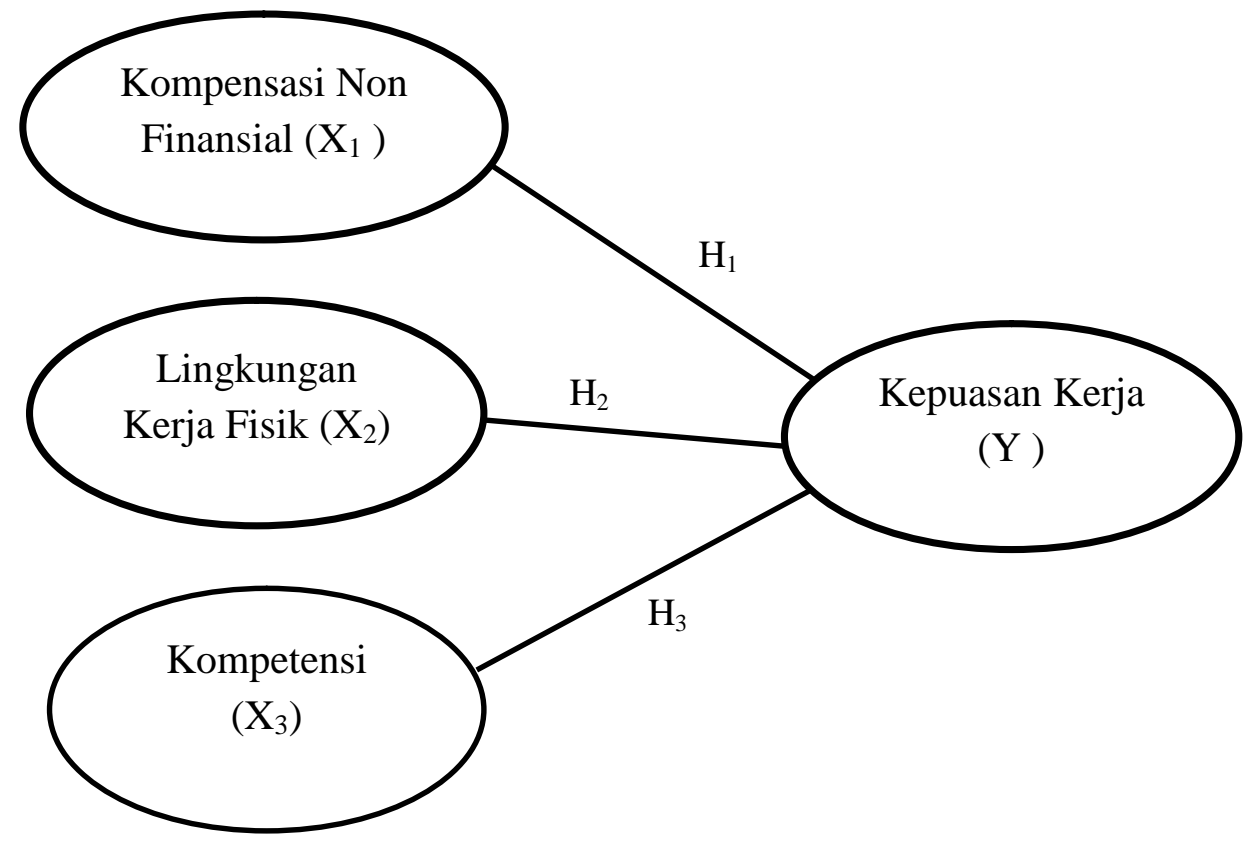

\section{Gambar 1. Kerangka Konseptual Penelitian}

Sumber:

$\mathrm{H}_{1}$ : Tobing (2009), Pratama, dkk., 2014, Reskiputri (2015)

$\mathrm{H}_{2}$ : Reskiputri (2015), Wibowo, dkk (2014), Wahyudi (2013), Septiadi, dan Supartha (2013)

$\mathrm{H}_{3}$ : Boyatzis dalam Hutapea dan Thoha (2008), Mangkunegara (2009 : 41)

\section{METODE PENELITIAN}

Penelitian ini menggunakan penelitian asosiatif (hubungan) karena dalam penelitian ini mempunyai tujuan untuk mengetahui pengaruh sebab akibat dari variabel-variabel yang diteliti (Sugiyono, 2013:5). Variabel yang diteliti dalam penelitian ini adalah kompensasi non finansial $\left(\mathrm{X}_{1}\right)$, lingkungan kerja fisik $\left(\mathrm{X}_{2}\right)$ 
dan Kompetensi $\left(\mathrm{X}_{3}\right)$ sebagai variabel bebas, serta kepuasan kerja $(\mathrm{Y})$ sebagai variabel terikat.

Lokasi penelitian ini dilakukan di PT. Bank Perkreditan Rakyat Tish Gianyar yang beralamat di Jln. Raya Batubulan No. 27X Kecamatan Sukawati, Kabupaten Gianyar. Lokasi ini dipilih karena tersedianya data yang memadai dan mampu untuk diolah penulis lebih lanjut dan adanya kemudahan dari pimpinan perusahaan dalam mengumpulkan data penelitian sehingga dapat menghemat biaya, dan waktu. Sedangkan subyek dalam penelitian ini adalah seluruh karyawan PT. Bank Perkreditan Rakyat Tish Gianyar. Obyek penelitian ini adalah perilaku karyawan khususnya mengenai kepuasan kerja yang dipengaruhi oleh kompensasi non finansial, lingkungan kerja fisik dan kompetensi karyawan.

Variabel terikat dalam penelitian ini adalah kepuasan kerja karyawan (Y) yang diukur dengan menggunakan lima indikator yaitu beban kerja, gaji, kenaikan jabatan, pengawas, dan rekan kerja. Variabel bebas dalam penelitian ini adalah kompensasi non finansial $\left(\mathrm{X}_{1}\right)$, lingkungan kerja fisik $\left(\mathrm{X}_{2}\right)$ dan kompetensi $\left(\mathrm{X}_{3}\right)$ yang masing-masing diukur dengan menggunakan indikator. Kompensasi non finansial $\left(\mathrm{X}_{1}\right)$ diukur dengan menggunakan lima indikator yaitu rasa aman dalam bekerja, hubungan kerja yang harmonis, kesempatan berkarir, penghargaan, dan perhatian terhadap pemikiran karyawan. Lingkungan kerja fisik $\left(\mathrm{X}_{2}\right)$ diukur dengan menggunakan lima indikator yaitu penerangan di ruangan kerja, sirkulasi udara, penggunaan warna, tingkat kebisingan, dan keamanan kerja. Kompetensi $\left(\mathrm{X}_{3}\right)$ diukur dengan menggunakan lima indikator yaitu pengetahuan, pemahaman, sikap kerja, kemampuan, dan minat. 
Jenis data yang digunakan dalam penelitian ini adalah data kuantitatif berupa jumlah karyawan pada PT. Bank Perkreditan Rakyat Tish Gianyar dan tabulasi dari jawaban kuesioner dari daftar pertanyaan dalam kuesioner. Data kualitatif berupa gambaran umum perusahaan dan penilaian responden terhadap pertanyaan-pertanyaan yang diajukan dalam kuisioner. Sedangkan sumber data yang digunakan dalam penelitian ini adalah sumber primer berupa hasil wawancara dan pemberian kuisioner terhadap responden. Sumber sekunder berupa data perusahaan yang diperoleh berdasarkan dokumen-dokumen yang sudah ada dalam perusahaan, seperti sejarah singkat, dan gambaran umum perusahaan.

Populasi dalam penelitian ini adalah seluruh karyawan pada PT. Bank Perkreditan Rakyat Tish Gianyar. Sedangkan sampel yang digunakan dalam penelitian ini adalah seluruh karyawan PT. Bank Perkreditan Rakyat Tish Gianyar yang berjumlah 39 orang. Dengan metode penentuan sampling jenuh yaitu teknik penentuan sampel bila semua anggota populasi digunakan sebagai sampel (Sugiyono, 2013:122).

Metode pengumpulan data yang digunakan dalam penelitian ini adalah observasi berupa pengamatan langsung aktivitas kerja karyawan. Kuesioner berupa pengumpulan data dengan menggunakan daftar pertanyaan yang diberikan kepada para responden berkaitan dengan tujuan penelitian. Wawancara dilakukan dengan tanya jawab untuk mendapatkan keterangan yang berhubungan dengan objek penelitian. 
Skala yang digunakan dalam penelitian ini yaitu skala Likert, yang digunakan untuk mengukur sikap, pendapat, dan persepsi seseorang atau sekelompok orang tentang adanya fenomenal sosial (Sugiyono, 2013:132). Kuesioner akan menggunakan lima titik skala Likert, dengan nilai. STS $=1$ (sangat tidak setuju), TS $=2$ (tidak setuju), $\mathrm{CS}=3$ (cukup setuju), $\mathrm{S}=4$ (setuju), dan SS = 5 (sangat setuju)

Teknik analisis data yang digunakan dalam penelitian ini adalah teknik analisis regresi linear berganda. Uji asumsi klasik dilakukan terlebih dahulu untuk mengetaui ada atau tidaknya penyimpangan serta mengkonfirmasi hipotesis berupa uji normalitas, multikolinearitas, dan heteroskedastisitas. Model regresi linear berganda dirumuskan sebagai berikut.

$$
\mathrm{Y}=\mathrm{a}+\mathrm{b}_{1} \mathrm{X}_{1}+\mathrm{b}_{2} \mathrm{X}_{2}+\mathrm{b}_{3} \mathrm{X}_{3}+\mu
$$

Keterangan:

$\mathrm{Y} \quad=$ kepuasan kerja

$\mathrm{X}_{1} \quad=$ kompensasi non finansial

$\mathrm{X}_{2} \quad=$ lingkungan kerja fisik

$\mathrm{X}_{3}=$ kompetensi

$\mu \quad=$ Variabel pengganggu yang berpengaruh terhadap $\mathrm{Y}$ tetapi tidak dimaksudkan dalarn model

a = Bilangan Konstanta

$b_{1}-b_{2}-b_{3}=$ Koefisien regresi variabel $X_{1}-X_{2}-X_{3}$

\section{HASIL DAN PEMBAHASAN}

Berdasarkan data dari 39 responden yang merupakan karyawan PT BPR Tish di Kabupaten Gianyar, dapat digambarkan karakteristik responden yang 
diklasifikasikan dalam jenis kelamin, usia, pendidikan dan masa kerja yang dapat dilihat pada Tabel 2 .

Tabel 2.

Karakteristik Responden Penelitian

\begin{tabular}{|c|c|c|c|}
\hline No & Kriteria & Jumlah Responden (orang) & Persentase \\
\hline \multirow[t]{4}{*}{1.} & Jenis Kelamin & & \\
\hline & a. Laki-laki & 15 & 38,46 \\
\hline & b. Perempuan & 24 & 61,54 \\
\hline & Jumlah & 39 & 100,00 \\
\hline \multirow[t]{5}{*}{2.} & Usia & & \\
\hline & a. $20-25$ Tahun & 12 & 30,76 \\
\hline & b. $26-30$ Tahun & 20 & 51,30 \\
\hline & c. $31-35$ Tahun & 7 & 17,94 \\
\hline & Jumlah & 39 & 100,00 \\
\hline \multirow[t]{5}{*}{3.} & Pendidikan & & \\
\hline & a. SLTA/Sederajat & 11 & 28,20 \\
\hline & b. Diploma & 19 & 48,72 \\
\hline & c. Sarjana & 9 & 23,07 \\
\hline & Jumlah & 39 & 100,00 \\
\hline \multirow[t]{7}{*}{4.} & Masa Kerja & & \\
\hline & a. $<1$ Tahun & 9 & 23,07 \\
\hline & b. $1-2,5$ Tahun & 6 & 15,38 \\
\hline & c. $2,6-5$ Tahun & 8 & 20,51 \\
\hline & d. $\quad 5,1-10$ Tahun & 11 & 28,21 \\
\hline & e. $>10$ Tahun & 5 & 12,82 \\
\hline & Jumlah & 39 & 100,00 \\
\hline
\end{tabular}

Sumber: Data diolah, 2018

Pada Tabel 2 menunjukkan empat karakteristik dari responden yang terdiri dari jenis kelamin, usia, tingkat pendidikan, dan masa kerja. Responden pada penelitian menunjukkan bahwa jenis kelamin laki-laki berjumlah 15 orang. Sedangkan jenis kelamin perempuan berjumlah 24 orang.

Usia dalam responden penelitian ini mulai dari 20 - 25 tahun sebanyak 12 orang, usia $26-30$ tahun sebanyak 20 orang atau sebesar 51,30 persen dan usia 31 tahun keatas sebanyak 7 orang. Tingkat pendidikan jumlah tertinggi terletak pada tingkat pendidikan diploma yang memiliki jumlah 19 orang, sedangkan 
jumlah yang terendah pada tingkat pendidikan Sarjana yang memiliki jumlah 9 orang.

Karakteristik masa kerja terdapat tiga bagian, masa kerja 0-1 tahun memiliki jumlah sebanyak 9 orang, masa kerja 1-2,5 tahun memiliki jumlah sebanyak 6 orang, masa kerja 2,6-5 tahun memiliki jumlah 8 orang, masa kerja 5,1-10 tahun memiliki jumlah 11 orang dan masa kerja lebih dari 10 tahun memiliki jumlah sebanyak 5 orang.

Uji validitas bertujuan untuk menguji sejauh mana intrumen yang digunakan dalam penelitian ini mampu mengukur variabel yang telah ditetapkan oleh peneliti. Suatu instrumen yang valid ditunjukkan dengan r Pearson Correlation skor total $\geq 0,30$.

Hasil uji validitas pada Tabel 3. diatas menunjukkan dalam uji ini syarat minimum suatu kuesioner untuk memenuhi validitas adalah jika $\mathrm{r}$ hitung bernilai $\geq \mathrm{r}$ batas sebesar 0,3. Dapat dilihat bahwa koefisien korelasi product moment tiap butir instrumen lebih besar dari syarat minimum yakni 0,3 , sehingga setiap butir instrumen dinyatakan valid.

Uji reliabilitas mampu menunjukan sejauh mana instrument dapat dipercaya dan diharapkan. Nilai suatu instrument dikatakan reliable apabila nilai Alpha Cronbach $\geq 0,6$. Hasil uji reliabilitas dapat dilihat pada Tabel 4 .

Hasil uji reliabilitas yang disajikan dalam Tabel 4. dalam uji ini syarat minimum suatu kuesioner untuk memenuhi reliabilitas adalah jika nilai cronbach's alpha bernilai $\geq 0,6$. Dapat dilihat bahwa setiap nilai cronbach's 
alphalebih besar dari syarat minimum yakni 0,6, sehingga setiap kuesioner dinyatakan reliable.

Tabel 3.

Hasil Uji Validitas Instrumen

\begin{tabular}{clcccc}
\hline No & \multicolumn{1}{c}{ Variabel } & Nomor Item & r-hitung & r-batas & Keterangan \\
\hline 1. & Kompensasi Non & 1 & 0,874 & 0,3 & Valid \\
& Finansial $\left(\mathrm{X}_{1}\right)$ & 2 & 0,847 & 0,3 & Valid \\
& & 3 & 0,835 & 0,3 & Valid \\
& & 4 & 0,854 & 0,3 & Valid \\
& & 5 & 0,824 & 0,3 & Valid \\
2 & Lingkungan Kerja Fisik & 1 & 0,633 & 0,3 & Valid \\
& ( $\left.\mathrm{X}_{2}\right)$ & 2 & 0,650 & 0,3 & Valid \\
& & 3 & 0,729 & 0,3 & Valid \\
& & 4 & 0,806 & 0,3 & Valid \\
& & 5 & 0,775 & 0,3 & Valid \\
& & 1 & 0,701 & 0,3 & Valid \\
& & 2 & 0,767 & 0,3 & Valid \\
& & 3 & 0,795 & 0,3 & Valid \\
& & 4 & 0,788 & 0,3 & Valid \\
& & 5 & 0,789 & 0,3 & Valid \\
4 & \multirow{2}{*}{ Kepuasan Kerja $(\mathrm{Y})$} & 1 & 0,822 & 0,3 & Valid \\
& & 2 & 0,672 & 0,3 & Valid \\
& & 3 & 0,775 & 0,3 & Valid \\
& & 4 & 0,903 & 0,3 & Valid \\
& & 5 & 0,930 & 0,3 & Valid \\
\hline
\end{tabular}

Sumber : Data diolah, 2018

Tabel 4.

Hasil Uji Reliabilitas Instrumen

\begin{tabular}{lccc}
\hline Instrumen Penelitian & Cronbach'sAlpha & $\begin{array}{c}\text { Batas } \\
\text { Reliabilitas }\end{array}$ & Keterangan \\
\hline Kompensasi Non Finansial $\left(\mathrm{X}_{1}\right)$ & 0,896 & 0,6 & Reliabel \\
Lingkungan Kerja Fisik $\left(\mathrm{X}_{2}\right)$ & 0,762 & 0,6 & Reliabel \\
Kompetensi $\left(\mathrm{X}_{3}\right)$ & 0,825 & 0,6 & Reliabel \\
Kepuasan Kerja $(\mathrm{Y})$ & 0,865 & 0,6 & Reliabel \\
\hline Sumber : Data diolah, 2018 & & &
\end{tabular}

Uji normalitas menggunakan uji Kolmogorov-Smirnov, dengan uji ini dapat diketahui data yang digunakan berdistribusi normal atau tidak. Apabila Sign t hitung $>0.05$, maka data tersebut berdistribusi normal dan begitu juga sebaliknya (Santoso, 2001). 
Tabel 5.

Hasil Uji Normalitas dengan Analisis Kolmogorov-Sminarnov

\begin{tabular}{llr}
\hline & & Unstandardized Residual \\
\hline $\mathrm{N}$ & & 39 \\
Normal Parameter & Mean & .0000000 \\
& Std. Deviation & .77185542 \\
Most Extreme Differences & Absolute & .118 \\
& Positive & .097 \\
& Negative & -.118 \\
Test Statistic & & .118 \\
Asymp. Sig. (2-tailed) & & $.190^{c}$ \\
\hline Sumber: Data diolah, 2018 & &
\end{tabular}

Hasil uji normalitas dengan menggunakan Kolmogorov-Smirnov pada Tabel 5. menunjukkan nilai signifikan Kolmogorov-Smirnov sebesar 0,190. Hasil tersebut menunjukkan bahwa nilai signifikansi 0,190 lebih besar dari 0,05 $(0,190>$ 0,05) maka dapat disimpulkan data penelitian berasal dari populasi yang berdistribusi normal.

Uji multikolinieritas digunakan untuk mengetahui apakah antara variabel bebas terjadi multikolinieritas atau tidak. Uji yang digunakan yaitu dengan melihat nilai VIF (Varian Inflation Factor) dan Tolerance pada proses regresi biasa, jika keduanya mendekati 1 atau besaran VIF kurang dari 10 maka model tidak terkena multikolinieritas. Berdasasrkan hasil pengujian multikolinearitas dapat diperoleh hasil sebagai berikut.

Tabel 6.

Hasil Uji Multikoleniaritas

\begin{tabular}{lccc}
\hline \multicolumn{1}{c}{ Model } & & \multicolumn{2}{c}{ Collinearity Statistics } \\
\hline 1 & X1 & Tolerance & VIF \\
& X2 & .443 & 2.255 \\
& X3 & .458 & 2.183 \\
& & .467 & 2.143 \\
\hline
\end{tabular}

Sumber: Data diolah,2018 
Hasil uji multikolinieritas dapat dilihat pada tabel 6. yang menunjukkan bahwa hasil perhitungan nilai tolerance semua variabel bebas mempunyai nilai lebih tinggi dari 0,10 begitu juga VIF semua variabel bebas mempunyai nilai kurang dari 10 yang artinya tidak ada korelasi antar variabel bebas. Variabel $\mathrm{X}_{1}$ mempunyai tolerance value sebesar $0,443>0,10$ dan VIF sebesar $2,255<10$. Variabel $\mathrm{X}_{2}$ mempunyai tolerance value sebesar 0,458> 0,10 dan VIF sebesar $2,183<10$. Variabel $\mathrm{X}_{3}$ mempunyai tolerance value sebesar $0,467>0,10$ dan VIF sebesar $2,143<10$. Oleh karena itu, dapat diambil kesimpulan bahwa tidak terdapat multikolinieritas pada model regresi penelitian.

Uji Heteroskedastisitas bertujuan untuk menguji apakah dalam model terjadi ketidaksamaan varian atau residual satu pengamatan ke pengamatan lainnya. Jika tingkat signifikan lebih besar dari 0,05 maka terjadi heteroskedastisitas.

\section{Tabel 7.}

Uji Heteroskedastisitas

\begin{tabular}{|c|c|c|c|c|c|c|}
\hline \multirow[b]{2}{*}{ Model } & & \multicolumn{2}{|c|}{$\begin{array}{c}\text { Unstandardized } \\
\text { Coefficients }\end{array}$} & \multirow{2}{*}{$\begin{array}{c}\text { Standardized } \\
\text { Coefficients } \\
\text { Beta }\end{array}$} & \multirow[b]{2}{*}{$\mathbf{t}$} & \multirow[b]{2}{*}{ Sig. } \\
\hline & & B & Std. Error & & & \\
\hline 1 & (Constant) & .432 & 1.154 & & .374 & .711 \\
\hline & $\mathrm{X} 1$ & -.051 & .050 & -.253 & -1.013 & .318 \\
\hline & $\mathrm{X} 2$ & .030 & .071 & .102 & .414 & .681 \\
\hline & $\mathrm{X} 3$ & .026 & .067 & .095 & .391 & .698 \\
\hline
\end{tabular}

Hasil uji heteroskedastisitas dapat dilihat pada tabel 7. yang menunjukkan bahwa semua nilai signifikan lebih dari 0,05. Dapat dilihat nilai signifikan pada variabel $\mathrm{X}_{1}$ sebesar $0,318(0,318>0,05)$, nilai signifikan pada variabel $\mathrm{X}_{2}$ sebesar $0,681(0,681>0,05)$ dannilai signifikan pada variabel $X_{3}$ sebesar $0,698(0,698>$ 
0,05). Oleh karena itu dapat disimpulkan bahwa tidak terjadi heteroskedastisitas pada data penelitian.

Sesuai dengan hasil perhitungan dengan menggunakan program SPSS for windows maka diperoleh hasil analisis regresi linear berganda.

Tabel 8.

Hasil Analisis Regresi Linier Berganda

\begin{tabular}{|c|c|c|c|c|c|c|}
\hline \multirow[b]{2}{*}{ Model } & & \multicolumn{2}{|c|}{ Unstandardized Coefficients } & \multirow{2}{*}{$\begin{array}{c}\text { Standardized } \\
\text { Coefficients } \\
\text { Beta }\end{array}$} & \multirow[b]{2}{*}{$\mathbf{t}$} & \multirow[b]{2}{*}{ Sig. } \\
\hline & & B & Std. Error & & & \\
\hline \multirow[t]{4}{*}{1} & (Constant) & .287 & 1.769 & & .162 & .872 \\
\hline & $\mathrm{X} 1$ & .356 & .077 & .459 & 4.614 & .000 \\
\hline & $\mathrm{X} 2$ & .328 & .110 & .293 & 2.995 & .005 \\
\hline & X3 & .298 & .102 & .283 & 2.920 & .006 \\
\hline
\end{tabular}

Sumber : Data diolah, 2017

Berdasarkan hasil analisis regresi linier berganda seperti yang disajikan pada Tabel 8., maka persamaan strukturalnya adalah sebagai berikut $Y=0,287+0,356 X_{1}+0,328 X_{2}+0,298 X_{3}$

Pada uji ini digunakan nilai $\mathrm{R}^{2}$, dimana nilai $\mathrm{R}^{2}$ dapat naik atau turun apabila satu variabel bebas ditambahkan ke dalam model.

\section{Tabel 9.}

Hasil Uji Koefisien Determinasi

\begin{tabular}{ccccc}
\hline Model & $\boldsymbol{R}$ & $\boldsymbol{R}$ Square & Adjusted $\boldsymbol{R}$ Square & Std. Error of the Estimate \\
\hline 1 & $.920^{\mathrm{a}}$ & .846 & .833 & .804 \\
\hline Sumber $:$ Data diolah, 2018 & & &
\end{tabular}

Berdasarkan Tabel 9, ditujukkan bahwa hasil analisis koefisien determinasi dapat terlihat dari $R$ Square sebesar 0,846. Hal ini mengindikasikan bahwa kontribusi $\mathrm{X}_{1}, \mathrm{X}_{2}$ dan $\mathrm{X}_{3}$ sebesar 0,846 yang berarti besar pengaruh variabel bebas 
terhadap variabel terikatnya adalah $0,846 \times 100 \%=84,6 \%$, sedangkan sebesar 15,4\% dijelaskan oleh faktor-faktor lainnya yang tidak diuji dalam penelitian ini.

Uji kelayakan model (Uji F) bertujuan untuk mengetahui kelayakan model regresi linear berganda sebagai alat analisis yang menguji pengaruh variabel independen terhadap variabel dependen secara bersama. Apabila tingkat signifikan lebih dari $\alpha=0,05$ maka model regresi ini tidak layak untuk digunakan sebagai alat analisis (Ghozali, 2013:98). Dengan menggunakan bantuan aplikasi SPSS 24.0 for Windows diperoleh hasil uji F sebagai berikut.

Tabel 10.

Uji Kelayakan Model (F-test)

\begin{tabular}{llccccc}
\hline Model & & Sum of Squares & df & Mean Square & F & Sig. \\
\hline 1 & Regression & 124.797 & 3 & 41.599 & 64.312 & $.000^{\mathrm{b}}$ \\
& Residual & 22.639 & 35 & .647 & & \\
& Total & 147.436 & 38 & & & \\
\hline
\end{tabular}

Sumber : Data diolah, 2018

Berdasarkan output di atas nilai dari F hitung 64,312 dengan nilai signifikansi 0,000 (kurang dari 0,05) maka disimpulkan bahwa ada pengaruh yang signifikan dari variabel independen terhadap variabel dependen secara simultan (bersama-sama). Sehingga model penelitian dikatakan layak digunakan sebagai model regresi.

Uji parsial (uji t) disebut juga sebagai uji signifikan individual. Uji ini menunjukkan seberapa jauh pengaruh variabel independen secara parsial terhadap variabel dependen (Sugiyono, 2013:134). Uji t dilakukan untuk menguji signifikan koefisien korelasi kompensasi non finansial $\left(\mathrm{X}_{1}\right)$, lingkungan kerja fisik $\left(\mathrm{X}_{2}\right)$ dan kompetensi $\left(\mathrm{X}_{3}\right)$ dan kepuasan kerja $(\mathrm{Y})$. 
Kompensasi non finansial berpengaruh positif dan signifikan terhadap kepuasan kerja. Hal ini berarti apabila kompensasi non finansial semakin tinggi maka mengakibatkan kepuasan kerja semakin tinggi pula.. Nilai koefisien regresi kompensasi non finansial $\left(\mathrm{X}_{1}\right)$ sebesar 0,356 menyatakan bahwa setiap peningkatan kompensasi non finansial sebesar 1 satuan maka akan terjadi peningkatan kepuasan kerja sebesar 0,356 satuan. Nilai probabilitas yang lebih kecil dari $5 \%$ yaitu $0,000<0.05$ mengindikasikan bahwa kompensasi non finansial berpengaruh positif dan signifikan terhadap kepuasan kerja.

Tobing (2009) mengungkapkan bahwa kompensasi non finansiaal memiliki pengaruh yang positif dan signifikan terhadap kepuasan kerja pekerja. Dimana pekerja yang merasa puas dengan adanya kompensasi non finansial yang diperoleh akan menunjukkan peningkatan kinerjanya dengan memberikan pelayanan yang terbaik dan bekerja dengan maksimal. Penelitian yang dilakukan oleh (Pratama, dkk., 2014) yang menemukan bahwa kompensasi (finansial dan non finansial) berpengaruh signifikan terhadap kepuasan kerja karyawan. Demikian pula dengan penelitian yang dilakukan oleh Reskiputri (2015) menemukan bahwa kompensasi non finansial berpengaruh signifikan terhadap kepuasan kerja karyawan.

Lingkungan kerja fisik berpengaruh positif dan signifikan terhadap kepuasan kerja. Hal ini berarti apabila lingkungan kerja fisik semakin tinggi maka mengakibatkan kepuasan kerja semakin tinggi pula. Persamaan regresi yang diperoleh dari hasil analisis regresi liniear berganda adalah sebagai berikut: $Y=0,287+0,356 X_{1}+0,328 X_{2}+0,298 X_{3}$. Hal ini menunjukkan koefisien 
regresi $X_{2}$ sebesar 0,328 menyatakan bahwa setiap peningkatan lingkungan kerja fisik sebesar 1 satuan akan terjadi peningkatan kepuasan kerja sebesar 0,328 satuan. Nilai probabilitas yang lebih kecil dari 5\% yaitu $0,005<0,05$ mengindikasikan bahwa lingkungan kerja fisik berpengaruh positif dan signifikan terhadap kepuasan kerja.

Lingkungan kerja fisik yang baik akan memotivasi karyawan untuk bekerja lebih giat sehingga menghasilkan produk yang berkualitas, hal ini meciptakan kepuasan kerja bagi karyawan yang bersangkutan. Ini berarti lingkungan kerja fisik berpengaruh terhadap kepuasan kerja karyawan. Kondisi ini sesuai dengan hasil penelitian yang dilakukan oleh Reskiputri (2015) bahwa lingkungan kerja fisik berpengaruh signifikan terhadap kepuasan kerja karyawan. Disamping itu sesuai pula dengan hasil penelitian yang dilakukan oleh Wibowo, dkk (2014) yang menemukan bahwa lingkungan kerja fisik berpengaruh secara positif dan signifikan terhadap kepuasan kerja karyawan. Hasil penelitian ini sejalan dengan penelitian terdahulu yang dilakukan oleh Wahyudi (2013), Septiadi dan Supartha (2013).

Kompetensi berpengaruh positif dan signifikan terhadap kepuasan kerja. Hal ini berarti apabila kompetensi semakin tinggi maka mengakibatkan kepuasan kerja semakin tinggi pula. Persamaan regresi yang diperoleh dari hasil analisis regresi liniear berganda adalah: $Y=0,287+0,356 X_{1}+0,328 X_{2}+0,298 X_{3}$. Hal ini menunjukkan koefisien regresi $X_{3}$ sebesar 0,298 menyatakan bahwa setiap peningkatan kompetensi sebesar 1 satuan maka akan terjadi peningkatan kepuasan 
kerja sebesar 0,298 satuan. Nilai probabilitas yang lebih kecil dari 5\% yaitu 0,005 $<0,05$ mengindikasikan bahwa kompetensi berpengaruh positif dan signifikan terhadap kepuasan kerja.

Mangkunegara (2009: 41) menyatakan bahwa, kompetensi SDM adalah kompetensi yang berhubungan dengan pengetahuan, keterampilan dan karakteristik pribadi yang mempengaruhi secara langsung kepuasan kerjanya. Pernyataan tersebut mengindikasikan betapa pentingnya kompetensi bagi sumber daya manusia di dalam suatu organisasi ataupun perusahaan dalam rangka meningkatkan kepuasan kerja menuju kinerja yang lebih baik. Hasil penelitian ini sejalan dengan penelitian terdahulu yang dilakukan oleh Boyatzis dalam Hutapea dan Thoha (2008) yang menyatakan bahwa kompetensi berpengaruh positif dan signifikan terhadap kepuasan kerja.

Penelitian ini hanya meneliti tentang beberapa variabel kompensasi non finansial, lingkungan kerja fisik, kompetensi kerja dalam mengukur kepuasan kerja, kedepan agar dibandingkan dengan memilih variabel up to date yang mempengaruhi kepuasan kerja sesuai kondisi lokasi penelitian. Penelitian hanya memilih satu lokasi penelitian hanya di PT BPR Tish. Sehingga dapat digunakan untuk wilayah yang lebih luas. Sampel diambil dalam satu waktu tertentu (cross section) sedangkan lingkungan cepat berubah, sehingga penelitian ini penting dilakukan di masa yang akan datang.

\section{SIMPULAN}

Berdasarkan pembahasan hasil penelitian di atas, dapat disimpulkan bahwa Kompensasi Non Finansial berpengaruh positif dan signifikan terhadap kepuasan 
kerja pada karyawan PT. Bank Perkreditan Rakyat Tish Gianyar. Lingkungan Kerja Fisik berpengaruh positif dan signifikan terhadap kepuasan kerja pada karyawan PT. Bank Perkreditan Rakyat Tish Gianyar. Kompetensi berpengaruh positif dan signifikan terhadap kepuasan kerja pada karyawan PT. Bank Perkreditan Rakyat Tish Gianyar. Sedangkan saran yang dapat diberikan adalah untuk pihak perusahaan diharapkan memberikan pegawainya dalam mengemukakan pendapat, menciptakan suasana kerja yang nyaman sehingga pegawai nyaman dalam bekerja serta menempatkan pegawai sesuai dengan keahliannya. Untuk pegawai diharapkan pegawai mampu menempatkan diri sesuai dengan kondisi saat bekerja. Untuk peneliti selanjutnya dapat mempertimbangkan variabel-variabel lain yang dapat mempengaruhi kepuasan kerja, agar penelitian selanjutnya dapat digeneralisasi.

\section{REFERENSI}

Abdullah, R., Musa, M., Zahari, H. dan Rahman, R. (2011). The Study of Employee Satisfaction, Workplace and Communication to Wards Loyalty in Hotel Industry in Klang Valley Malaysia. International Journal of Business and Social Science, 2(3), 147-155.

Abraham, K. L. A., Shaw, K., and Mena, M. A. (2001). Managerial Competencies and the Managerial Performance Appraisal Process. Journal of Management Development, 20(10), 842-852.

Aditya, E. M. (2009). The Influence of Workplace Environment on Workers Welfare, Performance and Produktivity. Journal of The African Educational Research Network. 12(1), 141-149

Aityan, S. K. dan Gupta. (2011). Challenges of Employee Loyalty in Corporate America. Journal Research Article, Accepted Version. 2(2), 47-54.

Ardana, I. K., Mujiati, N. W., dan Utama, I. W. M. (2012). Manajemen Sumber Daya Manusia. Edisi Pertama. Yogyakarta: Graha Ilmu. 
Adeniji, A. A. (2011). Organizational Climate and Job Satisfaction Among Academic Staff in Some Selected Private Universities in Southwest Nigeria. Business Intelligence Journal, 4(1), 151-165.

Aziri, B. (2011). Job Satisfaction: Literatur Review. Management Research and Practice, 3(4), 77-86.

Bhutto, N. A., Minhoon, K. L., and Falah, D. B. (2012). A Comparative Study of Organizational Climate and Job Satisfaction in Public, Private and Foreign Banks. Canadian center of Science and Education, 8(4), 259-267.

Belias, D., Koustelios, A., George, V., and Labros, S. (2015). Organizational Culture and Job Satisfaction of Greek Banking Institutions. ProcediaSocial and Behavioral Sciences, 175, 314-323.

Bartkus, K. R., Howell, R. D., Parent, M. C. R., dan Hartman, C. L. (1997). Managerial Antecedents and Individual Consequences of Group Cohesiveness in Travel Service Selling. Journal of Travel Research, 37(4), 56- 63.

Cahyadi, A. (2013). Pengaruh Lingkungan Kerja Terhadap Manajemen Sumber Daya Manusia yang ada dilingkungan Kabupaten Lingga. Jurnal Ekonomi dan Manajemen, 1(2), 145-176.

Cekmecelioglu, H. G., and Ayse, G. T. U. (2012). Effects Of Emotional Intelligence On Job Satisfaction: An Empirical Study On Call Center Employees. Procedia-Social and Behavioral Sciences, 58, 363-369.

Ekawati, A. dan Wulandari, S. (2011). Perbedaan Jenis Kelamin Terhadap Kemampuan Siswa Dalam Mata Pelajaran Matematika (Studi Kasus Sekolah Dasar). Jurnal Ilmu Sosial, 3(1), 19-24.

Elkina, S. dan Mark, S. (2011). Gender Differences in Executive Compensation: Variation With Board Gender Composition and Time. Journal of Economics and Bussines, 63(1), 23-45.

Evawati. (2013). Pengaruh Budaya Organisasi Terhadap Loyalitas Perawat Bagian Anak Rumah Sakit Umum Daerah Tanggerang. Jurnal Ilmu Ekonomi dan Sosial, 1(3), 233-355.

Gjorgji, E. (2012). Work-Related BehavioralIntentions in Macedonia: Coping Strategis, Work Environment, Love of money, Job Satifaction, and Demographic Variables Management and Marketingg, 10(1), 373-391.

Ghozali, H. I. (2013). Aplikasi Analisis Multivariate Dengan Program IBM SPSS 21. Badan Penerbit Universitas Diponegoro 
Hassan, M. S. N., Ghulam, A. and Muhammad, I. S. (2013). Impact of High Performance Work Practices on Employee Loyalty and Financial Performance through Mediation of Employee Satisfaction: An Empirical Evidence from the Financial Sector of Pakistan. Middle-East Journal of Scientific Research, 16(8), 1037-1046.

Hutapea, T. (2008). Kompetensi Plus. Jakarta: PT Gramedia Pustaka Utama

Imran, R., Nadia, R. dan Maulina. (2013). Pengaruh Beban Kerja, Stres Kerja dan Lingkungan Kerja Terhadap Tingkat Turnover Pegawai PKU Jawa Barat. Jurnal Ekonomi dan Bisnis, 12(5), 143-154.

Irbayuni, S. (2012). Pengaruh Kompensasi, Kepuasan Kerja dan Komitmen Organisasi Terhadap Keinginan untuk Pindah Kerja pada PT. Surya Sumber Daya Energi Surabaya. Jurnal NeO-Bis, 6(1), 43-56.

Khan, W. E. dan Mutfi, O. (2012). Effect of Compensation on Motivating Employees in Public and Private Banks of Peshawar (BOK and UBL). Journal of Basic and Applied Scientific Research, 2(5), 4616-4623.

Kurniawan, M., Adistya, D., Djambur, H., dan Hamidah, N. U. (2014). Pengaruh Kompensasi terhadap Kepuasan Kerja dan Kinerja Karyawan Studi pada PT Prudential Life Assurance. Jurnal Administrasi Bisnis, 16(1), 1-8.

Kurniawan, S. T. dan Faustine, T. (2014). Pengaruh Komunikasi dan Kepuasan Kerja Karyawan terhadap Kinerja Karyawan Departemen Front Office Hotel "X" Surabaya. Jurnal Hospitality dan Manajemen Jasa, 1, 163-178.

Leblebici, D. (2012). Impact of Workplace Quality on Employee's Productivity: Case Study of a Bank in Turkey. Journal of Business Economics and Finance, 1(1), 38-49.

Mangkunegara, A. P. (2009). Evaluasi Kinerja SDM. Bandung: Refika Aditama.

Mathis, R. L. dan Jhon, H. J. (2011). Manajemen Sumber Daya Manusia. Buku I. Jakarta: Salemba Empat.

Muljani, N. (2002). Kompensasi Sebagai Motivator untuk Meningkatkan Kinerja Karyawan. Jurnal Manajemen dan Kewirausahaan. 4(2), 108-122.

Nongkeng, H., Armanu, E. A. T., dan Margono, S. (2011). Pengaruh Pemberdayaan, Komitmen Organisasional terhadap Kinerja dan Kepuasan Kerja Dosen (Persepsi Dosen Dipekerjakan PTS Kopertis Wilayah IX Sulawesi di Makassar). Jurnal Aplikasi Manajemen, 10(3), 547-588. 
Omar, M. W., Kamaruzaman, J., dan Harniyati, H. (2010). Employee Motivation, Workplace and its Impact on Employee Loyalty. World Applied Sciences Journal, 8(7), 871-873.

Omar, W. A., and Wan, F. H. (2013). Transformasional Leadership Style and Job Satisfaction relationship: A Study of Structural Equation Modeling (SEM). International Journal of Academic Research in Business and Social Sciences, 3(2), 346-365.

Ostroff, C. dan Leanne, E. A. (2003). Does Whom You Work With Matter? Effects of Referent Group Gender and Age Composition on Managers Compensation. Journal of Applied Psychology, 88(4), 725-740.

Pratama, A., Suryoko, S., dan Widiartanto. (2014). Pengaruh kompensasi, lingkungan kerja dan beban kerja terhadap loyalitas karyawan melalui kepuasaan kerja (studi kasus pada karyawan PT. Kawasan Berkat Nusantara Persero Jakarta). Jurnal Ilmu Administrasi bisnis, 4(1), 283-293

Puspitawati, N. M. D dan Riana, I. G. (2014). Pengaruh kepuasan kerja terhadap komitmen organisasional dan kualitas layanan. Jurnal Manajemen Strategi Bisnis dan Kewirausahaan, 8(1), 68-80.

Ramlall, S. (2009). Case Study: Strategic Human Resource Management at Mayo Clinic. Journal of Human Resource Education, 3(3), 13-35.

Rizky, P. L. dan Fajrianthi. (2012). Pengaruh Reputasi Negara Asal (Country Of Origin Reputation) Terhadap Kepercayaan (Trust) Pada Pembeli Produk Elektronik Merek Changhong China. Jurnal Psikologi Industri dan Organisasi, 1(2).

Setiawan, D. (2013). Pengaruh Gaya Kepemimpinan Transformasional dan Transaksional terhadap Kepuasan Kerja dan Kinerja Karyawan di PT. Tohitindo multi Craft Industries Kraian.

Suwatno, H. dan Priansa, D. J. (2011). Manajemen SDM dalam Oranisasi Publik dan Bisnis. Bandung: Alfabeta.

Sari, F. M. (2013). Pengaruh Kompetensi Dan Lingkungan Kerja Terhadap Kepuasan Kerja Dan Kinerja Guru Di Sd Negeri Kecamatan Gondang Mojokerto. Jurnal Ilmu Ekonomi \& Manajemen, 9(2), 137-153.

Shikdar, A. A. (2002). Identification of Ergonomic Issues That Affect Workers in Oilrigs in Desert Environment. International Journal of Occupational Safety and Ergonomic, 10(8), 169-177. 
Siswanti, R. (2010). Pengaruh Lingkungan Kerja, Kompensasi dan Beban Kerja Terhadap Loyalitas Kerja Pegawai Swasta di Lumajang Jawa Timur. Jurnal Manajemen dan Kewirausahaan, 24(3), 34-47.

Soegandhi, V. M., Eddy, M. S. dan Roy, S. (2013). Pengaruh Kepuasan Kerja dan Loyalitas Kerja Terhadap Organizational Citizenship Behavior pada Karyawan PT. Surya Timur Sakti Jatim. Agora, 1(1), 65-78.

Sugiyono. (2013). Metodologi Penelitian Bisnis. Bandung: Alfabeta

Suswardji, E., Rachmat, H., dan Tresna. (2012). Analisis Hubungan Kompensasi Dengan Prestasi Kerja Karyawan pada Rumah Sakit Islam Karawang. Jurnal Manajemen, 9(3), 787-797.

Septiadi, I. M. dan Supartha, W. G. (2013). Pengaruh Kepemimpinan, Komunikasi, dan Lingkungan Kerja Fisik Terhadap Kepuasan kerja Pada PT. BPR Sriartha Lestari Denpasar. E-Journal Universitas Udayana, 2(8), 986-1001.

Teck-Hong, T., dan Waheed, A. (2011). Herzberg's Motivation-Hygiene Theory and Job Satisfaction in the Malaysian Retail Sector: The Mediating Effect of Love of Money. Asian Academy Of Management Journal, 16(1).

Tobing, K. L. dan Diana, S. (2009). Pengaruh Komitmen Organisasional dan Kepuasan Kerja Terhadap Kinerja Karyawan PT. Perkebunan Nusantara III di Sumatera Utara. Jurnal Manajemen Dan Kewirausahaan, 11(10).

Umar, H. (2010). Metode Penelitian Untuk Skripsi dan Tesis Bisnis. Edisi Kedua. Jakarta: Rajawali Pers.

Utami, W. (2005). Manajemen Sumber Daya Manusia Lanjutan. Edisi Revisi. Jember: Universitas Jember.

Van, D. L., Cummings, I. L., dan Parks, J. M. (1995). Extra-Role Behaviors: In Pursuit of Construct and Definitional Clarity (a Bridge Over Muddled Waters). Research in Organizational Behavior, 17, 215-285.

Voon, M. L., Lo, M. C., Ngui, K. S., dan Ayob, N. B. (2011). The influence of Leadership Styles on Employee Job Satisfaction in Public Sector Organization Malaysia. International Journal of Business Management and Social Sciences, 2(1), 24-32.

Wibowo, M., Mochammad, A. M., dan Gunawan, E. N. (2014). Pengaruh Lingkungan Kerja Terhadap Kepuasan Kerja Karyawan (Studi pada Karyawan PT.Telekomunikasi Indonesia Tbk. Kandatel Malang). Jurnal Administrasi Bisnis, 16(1). 
I Made Dwi Putra Arimbawa, Pengaruh Kompensasi Non.....

Wahyudi, I. W. (2013). Pengaruh Pelaksanaan Kepemimpinan, Komunikasi, dan Lingkungan Kerja Fisik Terhadap Kepuasan kerja Pada PT. Karang Bali Asli Tur Denpasar. E-Journal Universitas Udayana, 2(10), 1229-1242.

Yaseen, A. (2013). Effect of Compensation Factors on Employee Satisfaction A Study of Doctor Dissatifaction in Punjab. International Journal of Human Resource Studies, 3(1), 142-157. 